Pak. j. sci. ind. res. Ser. B: biol. sci. 2019 62B(2) 122-132

\title{
Review
}

\section{Present and Future Prospective of Green Technologies}

\author{
Zaffar Ahmed Shaikh \\ Faculty of Computer Science and Information Technology, Benazir Bhutto Shaheed University, \\ Lyari, Karachi, Pakistan
}

(received November 6, 2017; revised March 8, 2018; accepted March 13, 2018)

\begin{abstract}
In the modern age, changes in climate, global warming, depletion of energy resources and other concerns related to the environment have prompted the development of green technologies. Scientists consider that the expansion in the echelons of the sustainable development will influence sustainable economics as well as societies. It will likewise have an extremely positive effect on supportability later on. Technical progressions in the cutting edge society symbolize human creativity and novelties. Conversely, that innovation has brought about the disturbance of ecology from a region to worldwide level. Green technologies have a positive prospect in addressing the necessities of monetary sustainability. But, factors concerning ecological and societal sustainability should be strengthened in a conjoint way. Environmental in addition to economic influence and effectiveness of an innovation ought to be broken down before the use of technologies. It ought to be a win-win circumstance while financial and economic and sustainable progressions are profoundly emphasized on. This review paper delivers a general idea of green technologies. The difficulties looked in progressing and executing green technologies and modern patterns that result in sustainability are moreover talked about. This review likewise portrays administrative strategies and fund associated issues.
\end{abstract}

Keywords: green technologies, clean technologies, sustainable development, sustainability

\section{Introduction}

Green technologies are environmentally friendly innovations that outcome in financial and social manageability (Klimova et al., 2016; Davison, 2001). Green technologies give the impression of a sound and erudite name, however, it implies save for clean technology. Green technologies were also recognized as environmental technologies in the past years (Huesemann and Huesemann, 2011). From the perspectives of Information System, green technologies incorporate eco-friendly products that help in decreasing the creation of Greenhouses Gases (GHG). Previously, they have been observed as an expensive alternative to inexpensive, unmanageable innovation which has been used through-out.

Sustainability by means of green technologies implies thinking of nature-accommodating or environmentally friendly innovations that address human issues and in the meantime limit generation of waste as well as shore up life at present and henceforth (Williams and Helm, 2011; Wheeler and Bijur, 2000). For that reason, sustainable improvement must be met entirely in social, economic and environment categories (Ahmed et al.

E-mail: zashaikh@bbsul.edu.pk
2016; BIAC, 2010). An outlook of green technologies has been provided in this paper. The difficulties encountered in progressing along with actualizing green technologies and modern drifts that cause sustainability are talked over. This paper likewise outlines policies concerning regulations and issues related to finance.

The remaining of the paper is arranged along these lines. The section 'The Present and Future Perspective of Green Technologies' discovers diverse areas of application of green technologies. The next section is 'The Current and Future Problems faced by Green Technologies', which describes problems that were confronted in the progression and implementation of green technologies. Additionally, the possible advantages of green technologies are outlined in the section on 'Growth Opportunities of Green Technologies'. In 'Conclusion' section the inferences of study, perspectives of the author and directions of future research have been provided.

Present and Future Perspective of Green Technologies. This section gives an outline of 14 present and future domains of application of green technologies where their executions have been made effectively. 
The domain of application of water treatment technology. Water is a fundamental component throughout life. A number of areas experience the ill effects of water tainting and shortage within the world. Water treatment is the procedure of expelling detrimental impurities from water. The ingredients that are undesirable may consist of pollutants of biological, chemical compounds in addition to physical nature creating it possible to be utilized as a part of different applications. Water treatment is actually the solution favored by numerous emerging or developing countries in order to lessen water stress. This solution might be centered on alternate points of view contingent upon applications, for example, industrial plus human activity (Clark and Macquarrie, 2008).

The five basic stages of water treatment scheme. The most well-known strategies for water treatment at the present time incorporates coagulation and flocculation, sedimentation, filtration, as well as purification (Fig. 1).

In most cases, coagulation and flocculation are often the initial phases of water treatment. All through this period, a chemical having a positive charge is added to the water and with the dirt, the negative charge is attached. This procedure separates external proteins from water that shape huge particles known as Floc (Aithal and Aithal, 2016). These expansive particles are then expelled through the process of sedimentation. Small particles that outflow from the stage of filtration are trapped by the filters. Most water treatment plants utilize innovative filtering systems for instance Nano filters and membrane filters with the implementation of modern green technologies in water treatment process (Dubey et al., 2017; BIAC, 2010). These mesh trap tiny particles (Jagarajan et al., 2017).

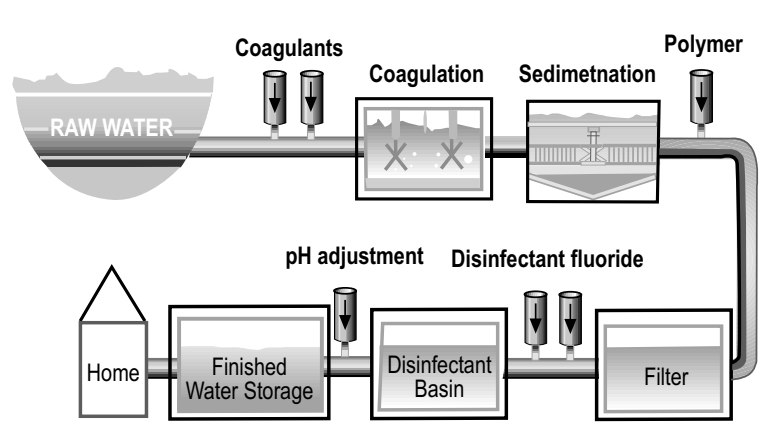

Fig. 1. Basic water treatment scheme.
The last stage is disinfection. This phase clears biological organisms; for example parasites, microscopic bacteria, viruses as well as protozoa (Aithal and Aithal, 2016). In the advanced treatment plants, chlorine and chlorimide are the usually accessible disinfectants. However, this procedure has demonstrated to cause a cancer-causing (carcinogenic) impact. In this manner, Ozonating is a procedure that is being included by numerous developing countries (BIAC, 2010).

For the sustenance of life, safe water is essentially required. As clean water can not be dictated by just physical examination, chemical tests are done to decide its standard. The fundamental components are required to be available and in the correct quality (Ahmed et al., 2016). The quality of the water is regulated by the World Health Organization (WHO) and the United States Environmental Protection Agency. Subsequent to treatment, water is not channeled to the households and industries; however, the quality tests are done till the water comes across the required standard by those bodies. These organizations have fixed policies of regulations that express the number of contaminants that can be present in the water of a particular zone. Each water treatment system needs to meet that standard of safe drinking water Act.

Almost every year regulatory laws are laid out by the WHO. In the year 2005, it was expected that about $94 \%$ of the reported cases of diarrhoea could have been lessened by treating water for daily consumption (Shah et al., 2014b; BIAC, 2010). The cure was to practice green technologies like chlorination, safe storage of cans, treatment by filtration plus solar. Such a manageability of water has been accomplished in lots of countries (Dubey et al., 2017; Jagarajan et al., 2017; Davison, 2001).

The domain of application of sewerage treatment technology. This portion depicts advancements in technology at the present time that take along sustainable wastewater treatments.

Wastewater treatment can be named as the way toward expelling solids, organics, and nutrition from the wastes of family units and organizations. The learning of the sewerage treatment has advanced from hundreds of years. In the cutting edge society, green technologies have been included in this domain to assist in getting rid of physical, biological and chemical contaminants from the runoffs to mark them environment-friendly (Jagarajan et al., 2017). Wastewater treatment has an 
impact that it enables the water from the industries to be dealt before being released back to the environment (Aithal and Aithal, 2016; Clark and Macquarrie, 2008). It is considered that the wastewater holds destructive compounds that will not just meddle with the nature of the environment, however, have the unfavorable complication in overall human health (Huesemann and Huesemann, 2011; Williams and Helm, 2011), while planning a wastewater treatment plant, the accompanying variables are put into the thought (BIAC, 2010):

- Removal of organic as well as biodegradable materials

- $\quad$ Extract the solid part

- Throw away pathogenic microbes

A systematic modeling of the treatment plant is presented in Fig. 2. Wastewater essentially happens in four phases:

- $\quad$ Screening

- Primary treatment

- Secondary treatment

- Final treatment

Screening is the primary phase of wastewater treatment. It expels big solids plus objects from wastewaters. The essential steps isolate the natural part of the waste through the sedimentation tanks where they go down and subside into the ground. The wastes that leave from the main treatment comprises of large amounts of Biochemical Oxygen Demand. Therefore, secondary treatment continues to separate the organic substances

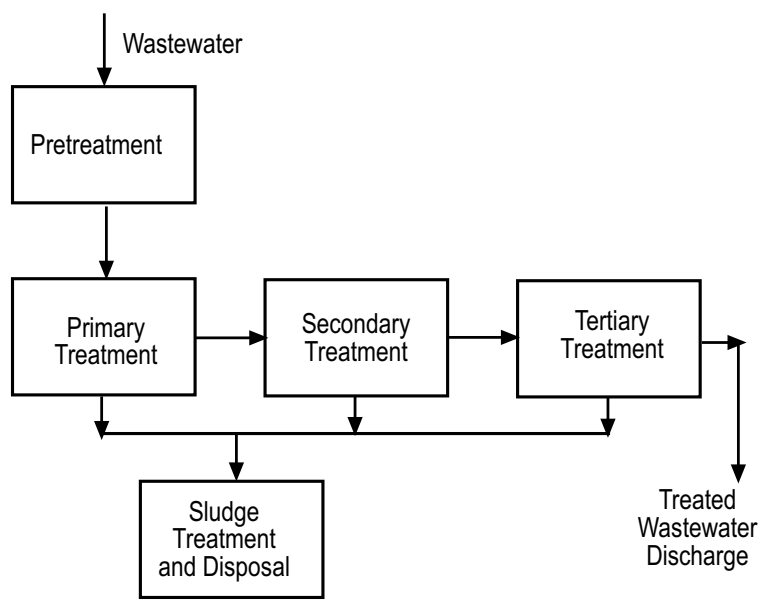

Fig. 2. Common steps involved in wastewater treatment. utilizing biological procedures (Ahmed et al., 2016). Wastewater encloses a number of different nutrients. The last stage decreases the amount of nutrients prior to discharge of wastewater into the streams (Williams and Helm, 2011).

Eutrophication is one of the antagonistic impacts that set in motion the degradation of the environment. The plants growing inside the water disturbs the levels of oxygen as well as carbon dioxide $\left(\mathrm{CO}_{2}\right)$ within the water bringing about the demise of the aquatic creatures (Aithal and Aithal, 2016).

The expanding level of ecological awareness has produced various industries and residences to set up techniques of green technology for recycling of wastewater (Aithal and Aithal, 2016; Garland, 2010). The regulatory standards set by the government and conservative bodies of environment compel the industry to look for innovations that limit wastewater being created and confirm recycling (Huesemann and Huesemann, 2011).

Green technologies have guaranteed that the wastewater generated by the industry and properties can be utilized in other zones such as irrigation and livestock along with watering in a dry and semi-arid region subsequent to the treatment (Jagarajan et al., 2017). As manufacturing industries are being planned, numerous have discovered the significance of making a recycling plant inside a similar plant to cut on the cost of managing wastewater (Dubey et al., 2017; Ahmed et al. 2016). The last water wasted might be used again in the process of manufacturing. The agreement is that it is less demanding to treat wastewater instead of formulating new plans of getting fresh water from the underground sources (Williams and Helm, 2011).

The innovation headways, such as the utilization of Microbial Fuel Cells have a bright prospect in feasible wastewater management (Garland, 2010; Clark and Macquarrie, 2008). Although innovation has stirred some technical hitches in the universal application financial practicality of the task, more research is continuous on the most proficient method to create the technology the piece of the upcoming prototypes of the sustainable wastewater treatment (BIAC, 2010; Garland, 2010; Wheeler and Bijur, 2000).

The domain of application of solid waste treatment and management technology. One of the most important facets of sustainability that has been fixated in the recent past is the solid waste (Klionsky et al., 2016; 
Davison, 2001). The solid waste manage-ment schemes supported by the government have given rise to the establishment of innovative technologies that decreases generation of waste (Paritosh et al., 2017; Williams and Helm, 2011).

According to the Product Stewardship Bill 2011, there's an inclination for each business to keep up concern and keep atmosphere free from perilous waste. These guidelines and codes are supposed to play an essential part in monetary and social expansion sustainability (Klimova et al., 2016; Davison, 2001). The waste transfers into the landfills have a conflict with ecological development. The rules for a sustainable development are intended to cover six stages as presented in Fig. 3 i.e., Reduce, Reuse, Recycle, Recover, Incinerate and Landfill (Williams and Helm, 2011). The disposing of waste within landfills goes in contradiction to the regulations and implies that new products will be prepared from scratch. The final products are that there will be an upsurge in the demands for fuel, energy and extra resources. Likewise, as the waste decomposes into these landfills, there is the formation and emission of GHG, for instance, $\mathrm{CO}_{2}$ and methane $\left(\mathrm{CH}_{4}\right)$ (Kumar and Sharma, 2017; Mahlia, 2002). The technology applied in waste management vary in unindustrialized as well as developed states, rustic to urban regions, and housing to industrial areas (Paritosh et al., 2017; Vostrikova and Gayevskaya, 2014; Clark and Macquarrie, 2008).

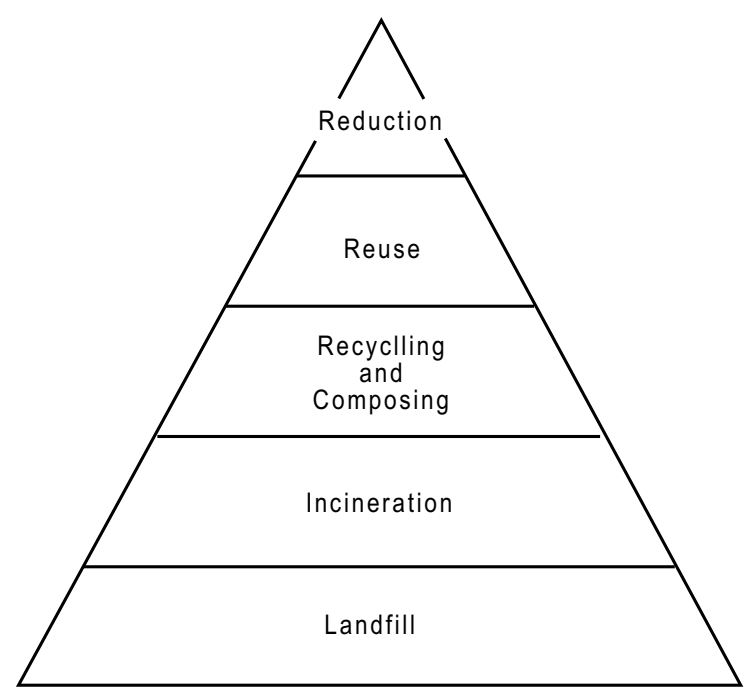

Fig. 3. Solid waste management hierarchy.
The technologies adopted by waste recovery industries from the past saw the waste discarded in the landfills manure to make fertilizers. Nonetheless, the most recent green innovations have resulted in the growth of aerobic digesters like bioreactors that incorporates the in-vessel usage of waste (Paritosh et al., 2017). The new headways in advancements not only manage wastes but also turn as a resource of renewable energy. Other waste management procedures take account of gasification and plasma synthesis, in addition to zero waste programmes ( $\mathrm{Li}$ et al., 2013).

The air purification technologies. Air pollution is to a great extent turning into a technical concern. Air pollution is the primer of detrimental chemicals as well as GHGs into the atmosphere. They give rise to human and animal diseases while end results are harmful to the atmosphere (Jagarajan et al., 2017; Llamas et al., 2016). Air pollution is thought to be a direct result of human attempts to do development. Industries and transportation devices are the common sources of pollution. Different gases, for example, sulphur dioxide $\left(\mathrm{SO}_{2}\right)$, nitric oxide $(\mathrm{NO})$, carbon monoxide $(\mathrm{CO})$ and more harmful gases are emitted in huge volumes. Air pollution has turned out to be a raising element after the GHGs have headed the diminution of the Ozone layer (Aithal and Aithal, 2016; Kumar and Sharma, 2016a).

Air filtration by means of green technologies has been supported in many industries. The greater part of the organizations reduces air pollution by the procedure of filtering GHGs in the process of emission (Kumar and Sharma, 2016b). One of the examples or case of technologies to decrease air pollution incorporates lead-free fuel along with the addition of catalytic converters. The acquaintance of those green technologies to trucks, buses as well as small vehicles will bring out a significant decrease in air pollutants (Jagarajan et al., 2017).

In the cutting edge world, more fuel-effective vehicles and hybrid electric autos have resulted the air pollutants reduction. These cars have decreased gasoline consumption by half. The advancements which have been executed in many urban communities have observed the reduction of air pollution in urban division (BIAC, 2010; Clark and Macquarrie, 2008). In the productions and industrial areas of the power plant, gas pollution has been reduced by filters in the emission chimneys. Albeit no present innovation has been set up to manage 
GHGs, for example, $\mathrm{CO}_{2}$, nume-rous industries have figured out how to reuse gases, like anaerobic bioreactors (Masutani and Coffin, 2001).

The environmental remediation technologies. This segment centers around green technologies that guide in the treatment of waste, help in the recycling process, dispense with or lessen dangerous wastes from the environment (Williams and Helm, 2011). Knowledge of environ-mental remediation has been progressing since the twentieth century. Environmental remediation can be named as the elimination of pollutants or different contaminants from the soil as well as waters. These pollutants can gather in living creatures and result in cancer-causing impacts and other poisonousness. In some conditions, actions of remediation can be a result of a regulatory requirement, after health evaluation of humans and general economic settings of the environment (Huesemann and Huesemann, 2011). Environmental remediation is a critical focal point of the green technologies intended for keeping up sustainability (Klimova et al., 2016; Klionsky et al., 2016).

The energy conservation technologies. Energy conservation alludes to the successful creation of energy that addresses current issues without trading off on future accessibility (Wheeler and Bijur, 2000). Green technologies have brought an inspiration to advance new sources of energy together with sustainable sources whilst that substitutes fossil fuels. The energy failure has by no means a problem with green technologies. In actual fact, they have made possible the introduction of gadgets that need the least amount of energy. At the end of the day, conservation of energy can be labeled as energy efficiency and is the most important mainstay of sustainable development (Jagarajan et al., 2017).

Green technologies make sure the decrease of gases created after burning of fossils fuels. Energy conservation will perceive an expansion in economic aspects, financial plus social security. Better-quality energy efficiency in residences, organizations, and transportation is required to decrease demand of energy by 2050s (Hebden, 2006). The green technologies have turned out to be valuable in a few countries since it has decelerated the speed of import and depending on the energy formed domestically.

The renewable energy technologies. Energy has grown into an imperative factor in economic evolution and social progress of any nation. With fast power usage emerging a worldwide challenge, the necessities to discover alternate and energy productive technologies have been initiated. Fossil fuels are utilized as a basis of energy for hundreds of years. By definition, fossil fuels are the substances where solar power is acquired, transformed into chemical energy and put away in plants and animals that have been passed on for decades (Shah et al., 2014a; BIAC, 2010). At the point when plants are followed up on to create energy, they give out GHGs. The GHGs give rise to adversative consequences for the environment and forthcoming generation (Kumar and Sharma, 2017; Huesemann and Huesemann, 2011).

A research study conducted in Malaysia in the year 2002 (Mahlia, 2002), presented that the prime source of electricity generation is the fossil fuels, as displayed in Table 1.

Sustainable energy sources, like hydro, solar, geothermal and biomass, are of pronounced importance to the sustainability of economics and environment (Klimova et al., 2016; Kumar and Sharma, 2016c; Davison, 2001).

Table 1. Emission factors of fossil fuels for electricity generation (Mahlia, 2002)

\begin{tabular}{lllll}
\hline \hline & \multicolumn{4}{c}{ Emission factor $(\mathrm{kg} / \mathrm{kWh})$} \\
\cline { 2 - 5 } Fuels & $\mathrm{CO}_{2}$ & $\mathrm{SO}_{2}$ & $\mathrm{NOx}$ & $\mathrm{CO}$ \\
\hline Coal & 1.1800 & 0.019 & 0.0052 & 0.0002 \\
Petroleum & 0.8500 & 0.0164 & 0.0025 & 0.0002 \\
Gas & 0.5300 & 0.0005 & 0.0009 & 0.0005 \\
\hline \hline
\end{tabular}

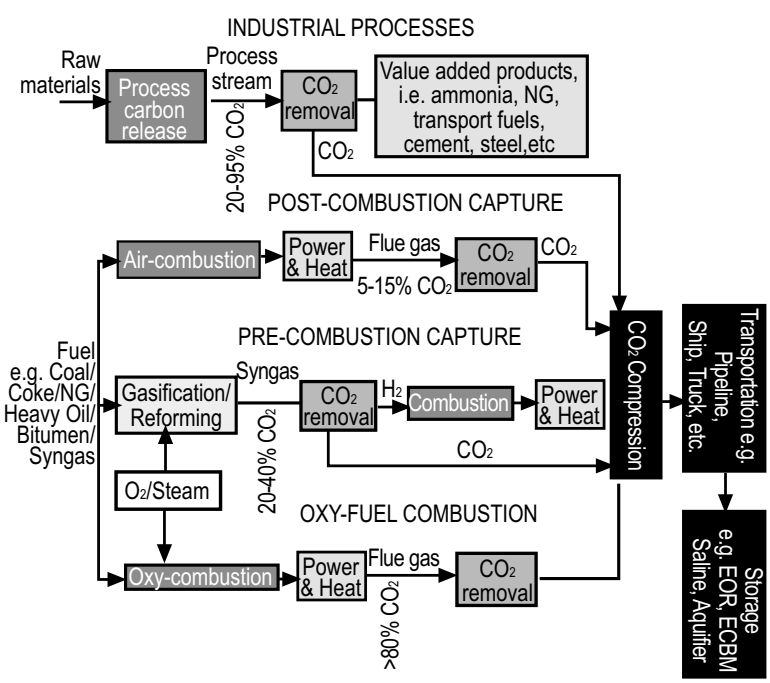

Fig. 4. Summary of $\mathrm{CO}_{2}$ capture technologies (Llamas et al., 2016). 
These clean technologies can result in the creation of substantial kWh with a lesser amount of release of GHGs (Jagarajan et al., 2017; Llamas et al., 2016). The International Energy Agency affirms that more than half $(50 \%)$ of electrical energy by the year 2050 will be from renewable sources of energy. Nevertheless, a long haul grid is necessary to attain sustainable renewable energy.

The capture and storage technologies. Capture and storage (CCS) is meant for decreasing GHGs discharge. $\mathrm{CCS}$ captures $\mathrm{CO}_{2}$ from the environment and stocks it in a sustainable surface. It takes after a 3-step process as clarified in Fig. 4. The procedure includes catching $\mathrm{CO}_{2}$ from power plants, carrying $\mathrm{CO}_{2}$ through pipes and storing of $\mathrm{CO}_{2}$ (Masutani and Coffin, 2001). CCS technology views $\mathrm{CO}_{2}$ set down in oil and gas recovery spots or un-mineable coal locales.

Despite the fact that technology of CCS appears to end in sustainability, it has just been halfway incorporated on a commercial scale (Llamas et al., 2016; Davison, 2001).

The technologies for green building practices. The topmost leading contributors of GHGs are conventional buildings. However, this part has focused on the offing of green buildings (Vostrikova and Gayevskaya, 2014; Ghaffarian Hoseini et al., 2013; Cassidy, 2003). In the wake of changes in climatic conditions like global warming, Green Building Practices (GBPs) are getting the worldwide acknowledgment (Aithal and Aithal, 2016; BIAC, 2010). The GBPs are eco-friendly and more financially reliable. Industries have come about with an innovative technology of building environment and nature-friendly houses.

The GBPs is a newfangled innovation in both technologically advanced as well as least developed nationstates. The research to see in what way GBPs adds to the sustainability of environment is yet substantial (Jagarajan et al., 2017; Klimova et al., 2016; Davison, 2001). However, as they are economically productive, the countries particularly the minimally developed countries have held onto the innovation as a sustainable progress (Li et al., 2013).

The cost of green buildings in general, is $2-7 \%$ greater than the usual conventional buildings with respect to the capital (Vostrikova and Gayevskaya, 2014). The money difference can be recommended to emerge from the cost of modeling and designing. Green technologies need a refined design which is expensive. The ascent of capital could likewise be a result of green materials, and green technologies utilized as a part of the venture (Cassidy, 2003). Despite the fact that green buildings are expensive, there are fiscal productivities as a consequence of GBPs. As noted before, green technologies are environmentally friendly, have more values of property, are more effective in energy and in particular, they are energy efficient (Ghaffarian Hoseini et al., 2013).

The influence of green buildings on atmosphere plus social life (Paritosh et al., 2017; Ghaffarian Hoseini et al., 2013; Huesemann and Huesemann, 2011; Cassidy, 2003) is achieved by:

- Efficient and productive utilization of reserves, for example, energy and water.

- Reduction of waste, water, and decrease in ecological degradation.

- Offering work to employees, consequently enhancing health and general profitability.

The technologies for sustainable transportation. Sustainable transportation is a system of transports that brings about positive influence on the environment. With present-day green technology being used in the manufacturing of green vehicles, there will remain reduced GHGs emission contrasted with standard cars, subsequently prompting a supportable environment (Jagarajan et al., 2017; Kumar and Sharma, 2016c; IAC, 2010). The sustainable transport system is stated by Environment Protection Agency as:

- A system of transport that enables society to rapidly satisfy the inclination or improvement at the level of individual being, organization or even group level supporting socio-economic and environmental health.

- A transport framework that is productive and underpins the competitive economy and possibly will cause economic progression.

- A sustainable system that decreases emission of GHGs by using an inexhaustible energy source and has less effect on the generation of waste.

The inclusion of electric hybrid cars causes a decline in $\mathrm{CO}_{2}$ emission in transport. The arrangement of hybrid cars is combustion engine that is internally designed with an electrical engine that aids in accomplishing sustainable transportation system (Kumar and Sharma, 2016a; Masutani and Coffin, 2001). 
The emergence and need of clean industries. The clean industry is a terminology indicated to industries that reduce ecological degradation. Clean industries include green technologies in the manufacturing of items and in due course activities that has sustainability outcomes (Klimova et al., 2016; Davison, 2001). The phrase clean industry is utilized alternately with green industry and could likewise allude to the companies that operate to solve challenges related to environment (Huesemann and Huesemann, 2011).

It is difficult to state the span of the spreading of green technologies globally as various nations are in a competition to see who's successful in the race of clean energy (Jagarajan et al., 2017). For instance, a report explored by Pew Charitable Trusts showed that $\$ 34.6$ billion of China's budget is spending on clean technology after that $\$ 18.6$ billion of United States' budget. Likewise, there are policy laws that have added to the expansion of the effective generation of clean products.

The hydrogen and fuel cell components. Hydrogen is an exceptionally uncommon component in the universe. Hydrogen can be separated from various sources, for example, coal, raw petroleum, flammable gas, and water. However, water is the main source known to be polluted (Ahmed et al., 2016; Cannon, 1995). With present day advancements, internal combustion engines in many autos can be adjusted to keep running on varieties of fuels together with hydrogen fuels. Vehicles that utilize hydrogen cell fuels are thrice more effectual as compared to those that burn gassed fuels within their engines (Richhariya et al., 2017; Garland, 2010; Cannon, 1995).

A Welsh physicist in 1842 discovered the first hydrogen fuel. Afterward, NASA utilized fuel cells to takeoff its shuttle interested in a space mission. Modern and social textures of the most nations around the world have transformed into Hydrogen and Fuel cells (Garland, 2010; McDowall and Eames, 2006). At present, numerous individuals trust that fuel cell technology will significantly affect new technological resurgence. These advancements are projected to be nature-friendly and will impact the economy in a positive way (McDowall and Eames, 2006). William Clay Ford said, "In today's world, solving environmental problems is an investment, not an expense" (Ford, 1998). The substantial traits that mark hydrogen cells more chosen above conventional fuel are that they certainly have no emission, and they are noiseless and off-load from vibrations (Garland, 2010; Cannon, 1995).
The agricultural technologies. Conventional agricultural technologies incur significant damage on nature. There is the outflow of GHGs, contamination of conduits and use of solid resources (Mahlia, 2002). Clean technologies in agricultural sector range from drip irrigation to less water use and from farming via machinery to natural pesticides. Investment within agricultural divisions is probably going to be impacted by cost adequacy, demands of consumer, mandatory regulations and interest of public (Kumar and Sharma, 2017; Richhariya et al., 2017).

The green technologies are being utilized to enhance the proficiency of planting and harvesting crop, usage of compounds for pests and weeds managing, fertilizer makings, protection from water pollution and mitigation of soil erosions (Jagarajan et al., 2017). Research organizations are examining practices of eco-farming for diminishing discharge of $\mathrm{CH}_{4}$, stock up soil carbon, made plus swap fossil fuels with the fuel produced using plant biomass (Kumar and Sharma, 2016b).

The current and future problems faced by green technologies. Innovations have affected our general public and its atmosphere from various perspectives and aided in developing more developed economies such as the present worldwide economy (McDowall and Eames, 2006). Green technologies are healing innovations for the environment. They limit damages to environment produced by technologies made by people for their comforts (Clark and Macquarrie, 2008). However, green technologies have been confronting challenges that make it harder to understand their set objectives. Such difficulties incorporate challenges of marketing, economies of scales, problems in financing, besides regulatory and technical encounters (Aithal and Aithal, 2016). Below described are significant challenges faced nowadays in executing green technology inventiveness, design plus manufacture.

The problem of development challenges. Green technologies have encountered untrustworthiness and interruption in supplies of fuel resource. They manage it hard to have a long-term fuel contract as lots of small programmes of renewable energy have the shortage of palm oil plantations and mills (Dubey et al., 2017). Associations among other electricity suppliers and green technologies are not sufficiently high to empower them to obtain energy supplies given by means of renewable sources. The utilization of renewables has been constrained by the point of price. The sustainable power source 
materials are costlier than accessible fossil fuel sources of energy. Moreover, availability of natural gas exhibits a noteworthy antagonism to the improvement of green technology advances (Richhariya et al., 2017).

Looking at the impacts and ramifications of national policy in instituting suggestions for suitable extension of technology has been a trial. There are no adequate advancements to analyze these suggestions. This has deferred programmes of green technology development as some of the national policy impacts are not outstanding (Jagarajan et al., 2017).

The problem of market challenges. Spreading out the business in green technologies in developing nations is generally distraught by the obstacles experienced amid the trade development. There is deficient learning about globally available eco-friendly innovations and the related services within the marketplace. This worldwide insufficient know-how regarding suppliers of green technology holds back the manufacturing of environmentfriendly green products. Besides, there are ecological and industrial perspectives and concerns consolidated in the planning of worldwide policies on the environment along with the trade.

The perplexing directions of arriving world's green technology markets keep off small as well as medium scale businesses. Furthermore, on the supply chain aspect of new product marketing, it requires the consumers a great deal of time to change from old items to the new ones. This procedure can be testing and long (Dubey et al., 2017). The green chemistry products have confronted opposition and obstacles to get complete approval. There is an absence of pact on products to be viewed as more secure for human usage (Jagarajan et al., 2017; Clark and Macquarrie, 2008; Clark, 2008).

The problem of technology advancements. The world needs satisfactory experts with abilities and learning matching green advances and the qualities it struggles for. For example, in green buildings, experts do not welcome all segments of green buildings. These incorporate ventilation, temperature and lighting control and additionally effective strategies for getting the energy that limits environmental harms (Aithal and Aithal, 2016; Huesemann and Huesemann, 2011; Cassidy, 2003).

As green technologies continue moving forward, it must stay aware of the most recent innovations to come across demands in order to exceed previous techniques for dealing with their businesses. For powerful correspondence with multiple countries, green technologies require real-time strategies to reach their data. Headways in Information and Communication Technologies are a trial that green technologies should constantly develop for them to flourish and accomplish their set objectives (Ghaffarianhoseini et al., 2013).

The problem of financing. Financing projects of renewable energy have considered being a critical encounter. Funding projects of sustainable energy, developers of small projects of renewable energy need to have a firm fiscal source. Further, they ought to be financially equipped for doing as such through value infusion instead of depending generally on business loans. The designers need sufficient assets to fund their tasks henceforth they begin to go stale. The Government has a duty to consider handing over a soft loan to support sustainable energy plans as national developments.

In the field of agriculture, green technologies have experienced difficulties of distinguishing appropriate technologies for creating earnings by the use of viable agriculture, similar to rustic renewable energy plus organic farming (Aithal and Aithal, 2016; Anwar et al., 2012).

The problem of regulations. Handling worldwide governing agreements with respect to green technologies are an obstacle that decelerates the improvement of green technologies. Though substantial investments are occurring inside the US, there are wide-ranging prospects for sustainable energy ventures in different other countries (Sohaib et al., 2015; Yang and Lam, 2013). Making those nations to go along with green technology regulations have shown unimaginable.

Associations governed by green technology ventures confront difficulties of recognizing, meeting and overseeing guidelines which fluctuate generally from nation to nation (Aithal and Aithal, 2016). Complex principles and code of practice of passage into the green technology global markets create it troublesome for medium sized as well as small enterprises to enter the marketplace by means of green technologies (Klimova et al., 2016). The viability in carrying out energy directions varies essentially starting with one country then onto the next. A number of countries need the authorization of government protocols to thrust toward the front of initiatives carried out by green technology. For instance, in the region of Asia, there are no guidelines on green building activities (Vostrikova and Gayevskaya, 
2014). Several nation-states have the green building plan, yet not all are supplemented with legitimate motivating forces or guidelines to initiate development (Li et al., 2013; Cassidy, 2003).

\section{The growth opportunities of green technologies.} Green technologies are composed of complex and costly method however, make the self-effacing technology advancements. They work for fundamental human needs and can search new potential outcomes of sightseeing and enhance solace as well as leisureliness in human breaths (Clark and Macquarrie, 2008). In the manufacture and development of more durable and energy effectual materials, green technologies provide innovative and fascinating openings in order to offer a consistent source of energy (Jagarajan et al., 2017; Clark and Macquarrie, 2008). New environment-friendly items and services can be made for the reason to enhance growth rate whilst utilizing least possible means and minimizing destruction to nature (Huesemann and Huesemann, 2011).

Diminishing the number of resources utilized as a part of creating green products would fundamentally lessen unfavorable effects, therefore sidestepping economic and environmental failure. Green technology marketplace has distinguished renewable energy, recycling of water and treatment facilities, the most significant elements for export prospects and growth. Green technologies have an opportunity to open a viable, influential green technology sector among developing nations. This can be significant in broadening and spreading out advancements in green technology besides help limit harms made by industrial progression (Aithal and Aithal, 2016).

\section{Conclusion}

The considerate of green technology trials are creating associated innovation economical and focused. The green technology inventions resolve or limit issues particularly in sectors of agriculture in addition to manufacturing.

The vast majority of these issues can be beaten through slowing up green technology developments if basic stages are well thought-out. For example, the governments must agree to subsidize projects of renewable energy when the proprietor is stuck due to the fiscal constraints. The government should set up focused financial baits. These may incorporate bringing local government charges down to empower import of inexhaustible materials for energy and advancing reception of green buildings within the market. In addition, expelling non-renewable energy source would reinforce financial spurs for green technology advances. Awareness of public as well as training faculty managing with green technology advances can give essential information vital for expertise to work proficiently. If people can figure out how to beat challenges experienced by green technologies, it can have numerous valuable purposes, for example, management of waste products, ignition by recycling, purification of water and air in addition to the use of energy monitoring gadgets. They will provide individuals the solace they require to spend their lives contentedly.

From the above points of interest, it can be presumed that green technologies are an absolute necessity in this day and age. Since traditional innovation is testing sustainability, green technologies ought to be voted for ensuring sustainability of eco-social surroundings. Despite the fact that there are a few weaknesses in the execution of clean technology, if we perceive its longhaul advantages, we besides our upcoming generations will clearly get the benefit (Wheeler and Bijur, 2000). Additionally, innovation will enable us to monitor our constrained sources. In this manner, the most straightforward approach to keep up economic, environmental and societal sustainability is via education.

Conflict of Interest. The authors declare no conflict of interest.

\section{References}

Ahmed, S., Ahmad, M., Swami, B.L., Ikram, S. 2016. A review on plants extract mediated synthesis of silver nanoparticles for antimicrobial applications: a green expertise. Journal of Advanced Research, 7: $17-28$

Aithal, P.S., Aithal, S. 2016. Opportunities and Challenges for Green Technology in $21^{\text {st }}$ Century. MPRA Paper No.73661, Germany, Online at https:// mpra.ub.uni-muenchen.de/73661

Anwar, M.M., Ahmed, M., Asghar, F. 2012. Air pollution as an environmental hazard; a case study Karna basti of Bahawalpur, Pakistan. Sindh University Research Journal-SURJ (Science Series), 44: 405410.

BIAC, 2010. Technology development and deployment to address green growth challenges, Business and Industry Advisory Committee, (BIAC), the voice of OECD Business, Paris, 4 pp. 
Cannon, J.S. 1995. Harnessing Hydrogen. The Key to Sustainable Transportation, 360 pp., INFORM Inc., New York, USA.

Cassidy, R. 2003. White paper on sustainability: A report on the green building movement. Supplement to Building Design and Construction, 11.03: $1-47$.

Clark, J.H., Macquarrie, D.J. (eds.), 2008. Handbook of Green Chemistry and Technology, 564 pp., John Wiley \& Sons, USA. ISBN 978-0-632-05715-3.

Davison, A. 2001. Technology and the Contested Meanings of Sustainability. 294 pp., SUNY Press, USA.

Dubey, R., Gunasekaran, A., Papadopoulos, T., Childe, S.J., Shibin, K.T., Wamba, S.F. 2017. Sustainable supply chain management: framework and further research directions. Journal of Cleaner Production, 142: 1119-1130.

Ford, W.C. 1998. Jr. Chairman and CEO, Ford Motor Company. https://media.ford.com/content/ fordmedia/fna/us/en/people/william-clay-ford-jrhtml

Garland, N.L. 2010. US Department of Energy Fuel Cell Technologies Program. In: $18^{\text {th }}$ World Hydrogen Energy Conference 2010-WHEC 2010 Proceedings Speeches and Plenary Talks. D. Stotten and B. Emonts (eds.), vol. 78, pp. 87-92. Julich, Germany.

Ghaffarianhoseini, A., Dahlan, N.D., Berardi, U., Ghaffarianhoseini, A., Makaremi, N., Ghaffarianhoseini, M. 2013. Sustainable energy performances of green buildings: A review of current theories, implementations and challenges. Renewable and Sustainable Energy Reviews, 25: 1-17.

Huesemann, M., Huesemann, J. 2011. Techno-Fix: Why Technology Won't Save Us or the Environment, 464 pp., New Society Publishers, USA.

Jagarajan, R., Asmoni, M.N.A.M., Mohammed, A.H., Jaafar, M.N., Mei, J.L.Y., Baba, M. 2017. Green retrofitting-A review of current status, implementations and challenges. Renewable and Sustainable Energy Reviews, 67: 1360-1368.

Klimova, A., Rondeau, E., Andersson, K., Porras, J., Rybin, A., Zaslavsky, A. 2016. An international Master's programme in green ICT as a contribution to sustainable development. Journal of Cleaner Production, 135: 223-239.

Klionsky, D.J., Abdelmohsen, K., Abe, A., Abedin, M.J., Abeliovich, H., Acevedo Arozena, A. 2016. Guidelines for the use and interpretation of assays for monitoring autophagy ( $3^{\text {rd }}$ edition). Autophagy,
12: $1-222$.

Kumar, A., Sharma, M.P. 2017. Estimation of greenhouse gas emissions from Koteshwar hydropower reservoir, India. Environmental Monitoring and Assessment, 189: 240.

Kumar, A., Sharma, M.P. 2016a. Assessment of risk of GHG emissions from Tehri Hydropower Reservoir, India. Human and Ecological Risk Assessment: An International Journal, 22: 71-85.

Kumar, A., Sharma, M.P. 2016b. Green house gas emissions from hydropower reservoirs: Policy and challenges. International Journal of Renewable Energy Research (IJRER), 6: 472-476.

Kumar, A., Sharma, M.P. 2016c. Carbon stock estimation in the catchment of Kotli Bhel 1A Hydroelectric Reservoir, Uttarakhand, India. Ecotoxicology and Environmental Safety, 134: 365-369.

Li, D.H., Yang, L., Lam, J.C. 2013. Zero energy buildings and sustainable development implications-A review: Energy, 54: 1-10.

Llamas, B., Navarrete, B., Vega, F., Rodriguez, E., Mazadiego, L.F., Cámara, Á., Otero, P. 2016. Greenhouse Gas Emissions-Carbon Capture, Storage and Utilisation. In: Greenhouse Gases. INTECH, DIO: $10.5772 / 63154$.

Mahlia, T.M.I. 2002. Emissions from electricity generation in Malaysia. Renewable Energy, 27: 293-300.

Masutani, S.M., Coffin, R.B. 2001. Research Activities on Marine Methane Hydrates and $\mathrm{CO}_{2}$ Sequestration. In: Proceedings of the $24^{\text {th }}$ Meeting of the Marine Facilities Panel of the US-Japan Cooperative Program in Natural Resources (UJNR), US Department of the Navy, Carderock Division, NSWC., Washington, DC, USA.

McDowall, W., Eames, M. 2006. Forecasts, scenarios, visions, backcasts and roadmaps to the hydrogen economy: A review of the hydrogen futures literature. Energy Policy, 34: 1236-1250.

Paritosh, K., Kushwaha, S.K., Yadav, M., Pareek, N., Chawade, A., Vivekanand, V. 2017. Food waste to energy: an overview of sustainable approaches for food waste management and nutrient recycling. BioMed Research International, Epub.doi.org/ 10.1155/2017/2370927.

Richhariya, G., Kumar, A., Tekasakul, P., Gupta, B. 2017. Natural dyes for dye sensitized solar cell: A review. Renewable and Sustainable Energy Reviews, 69: 705-718.

Shah, S., Rafique, S., Jumani, M. 2014a. Analyses on 
utilisation of solar energy as a sustainable source of clean water production. Sindh University Research Journal-SURJ (Science Series), 46: 315-318.

Shah, S., Jumani, M., Rafique, S. 2014b. Prospective study of solar energy as a sustainable energy source of electrical power generation. Sindh University Research Journal-SURJ (Science Series), 46: 469472.

Sohaib, Q., Soomro, N., Habib, M., Memon, A., Tariq, U. 2015. Comparative analysis of recycled PVC composites reinforced with nonmetals of printed circuit boards. Sindh University Research JournalSURJ (Science Series), 47: 431-436.

Vostrikova, E.V., Gayevskaya, Z.A. 2014. Modernization of residential buildings of the 1960s. In: Advanced Materials Research vol. 941, pp. 858-863, Trans Tech Publications, Switzerland.

Wheeler, K.A., Bijur, A.P. (eds.) 2000. Education for a Sustainable Future: A Paradigm of Hope for the $21^{\text {st }}$ Century Innovation in Science Education and Technology Series, vol. 7, pp. XVII, 280, Springer, USA.

Williams, M., Helm, A. 2011. Waste-to-energy success factors in Sweden and the United States. Analyzing the Tranferability of the Swedish Waste-to-Energy Model to the United States. pp.12. Available at: http://www.acore.org/wp-content/uploads/2012/ 04/WTE. 